\title{
What is (responsible) consumption? Discussing environment and consumption with children from different socioeconomic backgrounds in The Netherlands
}

\author{
Helen Kopnina
}

Published online: 29 March 2011

(c) The Author(s) 2011. This article is published with open access at Springerlink.com

\begin{abstract}
This research explores the attitudes of children from different socioeconomic backgrounds toward consumption with the aim of establishing a framework for incorporating the subject of (responsible) consumption into the upper elementary school curriculum. This study draws upon the four-step methodological procedure, including consumption diaries, focus-group sessions, interviews, and concept mapping, conducted among 140 upper elementary school children in the Netherlands between September 2010 and January 2011. The consumption diaries, chronological documents recording purchase, use and waste of materials, were used both as analytical tools and the means to stimulate environmental awareness. Comparison of the clusters generated by concept mapping analysis shows that there are significant differences between attitudes of children from different socioeconomic backgrounds. While pupils from the "well-to-do" predominantly ethnically Dutch schools showed greater awareness of and concern about their own consumptive patterns, children from less economically advantaged and ethnically mixed schools demonstrated lower environmental awareness and concern. However, children from the disadvantaged schools demonstrated more pro-environmental consumptive behaviors associated with the money-saving activities.
\end{abstract}

Keywords Consumption - Consumption diary · Environmental education (EE) - Elementary school children · Focus groups · Interviews - Concept mapping · Environmental anthropology

H. Kopnina $(\square)$

Amsterdam Institute of Advanced Labour Studies, University of Amsterdam, Amsterdam, The Netherlands e-mail: h.kopnina@uva.nl

\section{Introduction}

The questions guiding this research were: How aware are the children of their consumption patterns considering differences in socioeconomic backgrounds? Does socioeconomic and cultural background influence children's attitudes to consumption?

In order to answer the first question, children's attitudes toward consumption were tested using a pluralistic methodological approach involving the use of consumption diaries, focus groups, interviews, and concept mapping. This methodology and reflection on the resulting thematic clusters from which concept maps can be drawn will be discussed in the following section. The research upon which this article is based makes the first step toward answering the second question about the hypothesized influence on the consumptive attitudes of different sociocultural and economic background. The sample involved in this study contained upper elementary school children from the so-called mixed ethnic schools and pupils from socioeconomically underprivileged family backgrounds with those of well-to-do, predominantly ethnically Dutch schools. Thematic clusters generated by concept analysis of focus-group sessions and interviews with children were compared at the group level and showed that there are indeed some significant differences between environmental and consumption awareness between the groups. In order to fully address the second question, the influence of children's peer group, parents, teachers, and other stakeholders on their consumption and attitudes needs to be examined.

While there are many interdisciplinary studies of consumption conducted in the broad socioeconomic context (Sahlins 1976; Douglas and Isherwood 1978; Bourdieu 1984; Carrier and Heyman 1997; Shove et al. 2009), 
ethnographies of consumption practices (Wilk 1982; Miller 1995; Isenhour 2010), as well as studies of consumer behavior and environmental values (Ölander and ThØgersen 1995), there are limited studies of attitudes toward consumption, mainly addressed "between the lines" in general consumption-related studies. According to the review of Mayer and McPherson (2004), early research in the field of consumption addressed energy use in the home (Pallak et al. 1980), littering (Cialdini et al. 1990), and the reuse of materials (Burn 1991; Heckler 1994). More general studies of consumption and environmentalism (Lilienfeld 1998; Miller 1995), and garbage (Ritenbaugh 1984; Wilk 1982) did not link consumption to attitudes and learning. However, studies of consumption attitudes and behavior in children are lacking.

The subject of consumption is intertwined with societal and economic learning and thus directly related to environmental education (EE) through a number of considerations. First, an individual can influence the ecological world though consumption of goods and services. Chawla and Cushing (2007), for example, provide an overview of research on education aiming at enhancing behavior that decrease individual's negative impact on nature and increases life-sustaining actions. Individual patterns of consumption may in fact lead to societal change rendering alterations in production system through the adjustment of ecological impact.

Environmental learning in relation to consumption could be linked to economic aspects of citizenship education (Davies et al. 2002; Davies and Lundholm 2008), "private sphere" children's understanding of market forces (Leiser and Halachmi 2006), and reasoning about economic events (Sevón and Weckström 1989), while few explicit studies of consumption in children exist. Normative influence as well as moral reasoning and persuasion were shown to foster more responsible energy consumption (Aronson and O'Leary 1982; Gonzales et al. 1988). Similarly to the case of teaching complex issues such as climate change, teaching consumption provides an ideal context for introducing pupils to complex systems of the real world (Dahlberg 2001) and connect pupils to economic, socialpolitical and technical systems, regional and global production, and distribution channels (Shepardson et al. 2009). Relating to consumption holistically will require pupils to evoke both social science and scientific concepts. At upper elementary school level, this introduction to cross-disciplinary concepts will be cursory, leading to deeper emersion in both economic and natural science's insights into consumption in middle and high school. In contrast to recent European and national interest in EE, in general, there is a pronounced lack of interest in teaching responsible consumption, characteristics of and consequences of domestic consumption. While in accordance with the combined statistics from the United Nations Statistics Division, Economic Commission for Europe, and Economic Commission for Africa, Dutch consumption of, for example, energy per capita is hundred times higher than that of most citizens of the sub-Saharan Africa, EE in the Netherlands includes no information on (domestic) consumption.

There is a wealth of literature on the differences in environmental behavior and attitudes between different socioeconomic groups, but due to the scope of this article, we will only briefly touch upon the main theories and hypothesis that emerge from this body of research. Vast body of research has shown that consumptive practices and environmental awareness vary across nations. For example, in Van Petegem and Blieck's study employing New Ecological Paradigm (NEP) scale (for more details on NEP, see Dunlap and Van Liere 1978; Manoli et al. 2007 for the study of environmental attitudes in children), the authors found that children in Zimbabwe and Belgium displayed differences in ecological worldviews and particularly the human dominance dimension. Respondents in Belgium believe in human-nature equality, whereas Zimbabwean youngsters feel more dominant over nature and emphasize a utilitarian view of the environment.

Explanations of such national differences in perceptions are often rooted in childhood experiences with nature as a significant experience (Chawla and Cushing 2007:440). In line with Korhonen and Lappalainen (2004) and Wells and Lekies (2006) theory, Van Petergem and Blieck speculate that these differences could be explained by distinct experiences of the natural world acquired in early childhood as these influence environmental concern. The hypothesis that the early childhood encounters with nature are crucial for the development of positive environmental values is supported by retrospective reports of environmentalists, which are replete with stories of early and memorable encounters with pristine nature (Kahn and Kellert 2002). Relating this to this case study of the Dutch children, most of whom grew up in a country that lost some $90 \%$ of the original forest in the medieval times already due to agricultural developments and presently reside in the most highly populated countries in Western Europe, we would expect that their environmental values and attitudes will be low. This might be said to be in stark contrast with the experience of children growing up in developing countries who might have witnessed their pristine environment being encroached upon by Western development and yet exhibiting low environmental awareness. In line with Louv's reflective book, Last Child in The Woods (2005), however, we may speculate that the developedcountry children grow up with a very different kind of environmentalism, based on distant knowledge, rather than experience. For the consequent studies, the children 
participating in the studies similar to the one that the author describes might need to be screened for their earlier exposure to nature. This screening can be based on selfreports (confirmed by parents) through their life histories. The results need to be incorporated into analysis of proenvironmental values, especially in regard to consumption.

Another body of theories as to the differences in consumptive and environmental attitudes comes from studies conducted between different sociocultural groups within one nation. Young people in disadvantaged communities were likely to be more "conservationist" in their efforts to earn or save money (Kahn and Fridman 1995) in activities ranging from saving energy to buying clothes in the second-hand shops to participating in community projects to clean up the garbage (Hunter 2000; Hirsch et al. 2011). Sociodemographic variables were found to be important in understanding difference in energy consumption and emissions, suggesting that controlling for lifestyles and other determinants, emissions are increasing with income and decreasing with education (Baiocchi et al. 2010). Despite these pro-environmental behaviors and lower consumption levels than in the more socioeconomically advantaged groups, there is also evidence of lower environmental awareness and noneconomically motivated environmental behavior in such groups (Anderson et al. 2007). However, review of studies of regional differences and sociodemographic determinants of environmental concern demonstrate that research findings on such differences and determinants are inconsistent and occasionally contradictory due to lack of consensus on instrument to measure environmental attitudes (for a literature review, see Vining et al. 1992 and Guagnano and Markee 1995). Despite inconsistencies and contradictions, review of studies reveals that education is the only sociodemographic variable that had significant main effect on different measures of environmental concern (Guagnano and Markee 1995:147).

Recent research suggests that in understanding consumption patterns and sustainable living, the understanding of government and industrial elites' influenced social and political barriers to sustainable living is essential (Gardner and Stern 2002; Chawla and Cushing 2007; Isenhour 2010). In her investigation of the different groups of Swedish consumers, an anthropologist Cindy Isenhour suggests that "explorations of barriers to sustainable living is particularly salient when working with consumers who are already aware, interested, and engaged" (Isenhour 2010:461). Yet, in discussing political barriers, the researchers' group of responsible and informed consumers felt "helplessness that many people feel when they believe that their actions are insignificant given those of others, who do not seem to take responsibility" (Ibid, 462). The author of this article hypothesizes, however, that without understanding of the attitudes and behavior of different groups of consumers-particularly the next generation of consumers - the study of both pro-environmental and those not (yet) participating enough in the quest for sustainable living and responsible consumption is equally important.

In a research comparing the environmental attitudes and concern of native-born and foreign-born US residents, the authors found that immigrants engage in consumption behaviors protective of the environment, such as water saving, but have shown less environmental awareness and political engagement with the issues related to green consumption (Pffefer and Stycos 2002). This research is based on the hypothesis that the children from lower socioeconomic status group (in this case, immigrants) will indeed report more pro-environmental behaviors and lower consumption patterns associated with financial constraints, but also less environmental awareness than members of more economically well-to-do groups.

Some evidence in the case of environmental behavior and consumption attitudes in the case of Dutch children and adolescents is provided by the findings of the researcher groups Motivaction and YoungWorks, bundled in a report entitled Young Mentality and Sustainability (Lampert et al. 2010). Examining opinions of over a hundred children and adolescents between 12 and 18 years old, the researchers discovered that environmental attitudes, knowledge, and behavior greatly varied between the subgroups and individuals. The authors placed children in six groups in accordance with their pro-environmental and consumptive behaviors, ranging from Extravert Status seekers to "Independent Idealists." However, this research and publications were commissioned by the Dutch organization NME, Natuur en Milieuonderwijs [Nature and Environment education] mostly financed by the Dutch Ministries of Education and Welfare and appeared to be more commercial and policy-maker friendly than scientific. In this research's description, specifications of the sample or methodological strategy (apart from the mention of open interviews) are not given, findings oversimplified, while policy and pedagogical recommendations were easily drawn. While this research also intends to inform educational and policy specialists as to the divergent strategies of teaching different groups of pupils about environment and consumption, this research is just a first step to assess whether indeed such divergent groups exist and if so, outline directions for the group-sensitive curriculum development.

\section{The case study}

For this study, two schools participated in the study between September 2009 and May 2010 and one school 
Table 1 Sample of participants by school

\begin{tabular}{llll}
\hline Methodology & $\begin{array}{l}\text { Participants } \\
\text { school 1 }\end{array}$ & $\begin{array}{l}\text { Participants } \\
\text { school 2 }\end{array}$ & $\begin{array}{l}\text { Participants } \\
\text { school 3 }\end{array}$ \\
\hline Consumption diary & 31 & 60 & 49 \\
Focus group & 15 & 19 & 12 \\
Interview & 5 & 12 & 9 \\
Concept mapping & 31 & 60 & 49 \\
\hline
\end{tabular}

between May 2010 and January 2011. At all these schools, the children were selected by contacting their parents through the class mailing lists. The sample consisted of the elementary school children aged between 7 and 10 from two Dutch elementary schools in the Amsterdam area. One (Montessori) school contained a population of seventy-nine children aged between 7 and 10, and another (regular public) school contained a population of one hundred and twenty-two children of the same age. Both schools selected for this study were located in the predominantly "white" (ethnically Dutch), well-to-do areas of Amsterdam, with the parents' average income of 45,000 Euros per year (based on school records available and self-reports of parents whose consent was necessary for this study). The total number of children participants was 91 . The results of this study are reported in Kopnina (2011).

The previous study pointed out the need for the examination of different patterns of attitudes and behavior in children of different socioeconomic backgrounds and ethnic groups, as it was hypothesized that the children's consumption patterns and attitudes in more ethnically heterogeneous schools might show different data. Another case study was conducted at the third school between May 2010 and January 2011. This school was designated as "mixed" or "black" school as it contained $87 \%$ children of non-Dutch origin (mostly of Moroccan, Turkish, or Antillean heritage). The total number of children participants was 49. The parents' average income was approximated to be 20,000 Euros per year, and $60 \%$ of the parents were unemployed and/or collected disability benefits.

A total of 140 children participated in the study. The summary of the sample is indicated in the Table 1 below.

\section{Methodology}

This study employed the four-step methodology procedure to elicit information about the children and their parents' awareness of their consumption patterns. This procedure involved the use of consumption diaries by the children which were consequently discussed in mixed childrenparents' focus groups, followed by in-depth interviews with the children in order to generate statements that supplement those generated by focus groups for carrying out the concept mapping analysis on the subject of consumption. Qualitative data resulting from these sessions were organized through concept mapping analysis, which will be discussed in the following section.

Not all participants took part in all four steps of methodological procedure. Since the author was interested primarily in qualitative detailed investigation of a small sample, issues associated with the peculiarity of a sample and low response rates are partially justified for this study, but need to be addressed in case more vigorous study of this kind is undertaken. All these shortcomings are due to the fact that the present research constitutes a pilot study that lays a foundation for a more ambitious research of EE with special focus on consumption.

The simplest consumption diary (administered to the youngest segment of the children, between 7 and 8 years of age) consists of the following matrix: time of day (starting with "when you wake up" to "when you go to bed"), food and drink consumed, as well as waste products (specified as "for example, packaging"). Parents were asked to assist their children in completing this diary. The more advanced consumption diary (administered to the older segment of the children, between 8 and 9) consists of the same matrix, with addition of "energy" as separate categories. Finally, the age-group between 9 and 10 years is given an openended diary in which the children are asked to enter all consumed and disposed items, specifying in the introduction to the diary that they should consider food, drink, utilities use (such as water and electricity), and disposed items (including sanitary items). Other consumption items, such as objects (clothes, furniture, etc.), cultural (cinema, theater, etc.), and transportation (car, airplane, etc.), were excluded from the analysis due to the restrictions of the limited pilot study, but may be included in the consequent research design.

Parents and children received separate introductory letters. Invitation letters to parents contained basic information about the aim of the research and provided rationale for allowing their children to participate in this study. The letter specified that the consumption items were not to be perceived as "good" or "bad" but needed to be listed to open up a focus-group discussion. Children received a simplified version of this letter, inviting them to complete the diary. Multiple items could be entered in one time slot, but no room for clarifications or comments was allowed.

Consumption diaries alone, however, cannot fulfill an exhaustive study of consumption, but are helpful in conjunction with more qualitative study of behavior and attitudes, which focus groups and interviews provide. Consumption diaries completed by children with the assistance of their parents are neither objective nor concise as they only indicate the simplest types of consumed products (such as 
"food" or "drink") without quantifying these items (children are not asked, for example, how big or heavy their sandwich was) or specifying "quality," such as composition or origin (such as what type of bread was used for the sandwich and whether the tomato in it was locally grown). Rather, the entries in the diary serve as a starting point for opening a discussion about consumption items, as well as quantity, composition, and origin of the products consumed. Children were asked to reflect on their diaries together with their parents during the focus-group sessions and individual interviews. All the children were given rewards such as soft toys produced by World Wide Fund for Nature (WWF).

Focus-group sessions were organized at respective school's locations and were held twelve times, in groups of 7-10 participants. Meetings were held between September 2009 and January 2011 and lasted between 1 and 2 h. At each school, the concept mapping meetings were held, led by a facilitator. The term "sustainability" was explained using the formula "good for health and nature." During the focusgroup sessions, this term was discussed in greater detail, bridging the gap between parents' and children's ideas about "sustainability." Groups with older children participated in the discussion of "utilities," including water and electricity.

Discussion was guided by the focal question: "healthy and environmentally-friendly consumption should include the following...." At the first school, the meeting started with a 50-min brainstorm session during which participants were asked to formulate statements to complete the focal question. It needs to be noted that initially the author conceived the focal question without evoking "health," since the author believes that health and environment are not necessarily complementary to each other (Kopnina and Keune 2010).

In the interviews, the children were asked to reflect upon their consumption diaries, on the topic of consumption (what children understood it to be); consumption in general (with the interviewer specifying that consumption in itself is neither "good" nor "bad," but also introducing the idea of "global consumption" and "country differences"); the quantity and quality of consumed items (how much of what is being consumed, composition, and origin of consumed items); health effects of consumed items (which products are "good for one"); environmental effects (what implications can there be for "nature" and how "nature" is being understood in relation to consumption). Interviewer has consciously allowed children to take the discussion in any direction as long as it stayed anchored in these broad topics. Perceiving potential ethical difficulties, connected with possible value judgments about the harmful effects of consumption or the possibility of evoking guilt or denial, the interviewer attempted to only elicit opinions already present among the children rather than "educating" them about consumption. As in the case of focus-group discussions, the researcher stressed her own lack of knowledge or judgment on what is "good or bad" and her interest in what the children themselves thought about consumption. Interviews were recorded, transcribed and analyzed using the qualitative analysis software program MAXQDA. This program helped to generate a number of statements from both the focus group and interview transcripts that enabled the researcher to undertake the concept mapping analysis.

Focus-group sessions were conducted simultaneously with the concept mapping, which is commonly used to elicit ideas about complex issues in small groups and to map those ideas in a structured way at group level (Kane and Trochim 2007). The concept mapping method requires that statements are clear and do not contain multiple ideas. Therefore, the facilitator encouraged participants to clarify jargon and helped to edit the statements. Statements expressing similar ideas could be submitted only once. All statements were typed out on the computer and printed on a card. After a break, the participants received a complete set of cards. They were first asked to rate how important they considered each statement, using a five-point Likert scale: 1 (not important) and 5 (extremely important). They were then asked to sort the statements logically according to themes or clusters and to provide a name for each cluster. These tasks were performed individually, with a group facilitator helping the children. Subsequently, scoring forms were entered into the computer, and preliminary results generated by the concept mapping software (concept maps) were discussed in the group.

The statements generated at the first meeting were also the basis of the concept mapping at the third school. Here, participants were only invited to rate and sort the statements generated at the first school and to discuss the preliminary results. Following this procedure, the mean priority and standard deviations (SD) of the ratings the participants assigned to each statement were calculated at group level. This resulted in a rating list of statements. Multidimensional scaling techniques and cluster analysis were used to calculate how often statements were grouped into the same cluster. This resulted in a two-dimensional point map for each group. On these maps, statements that were more often placed under the same theme by the group members are located closer to each other. The researcher selected the final number of clusters, based on the proximity and the content of the statements. To identify similarities and differences between the children from different schools, the clusters they produced were compared by content analysis.

\section{Results: the children from schools 1 and 2}

Seventeen children participated in the in-depth interviews and thirty-four in focus-group sessions, and no separate 
matrix was made for children from school 1 and school 2 nor for younger and older children. Clusters contained items that sometimes semantically overlapped. Themes discussed in the 2-h session included questions of what responsible consumption is. These themes were largely organized under the "food," "drink," "waste," and "utility/energy" items.

The initial (and largest) focus-group discussion (which included a number of parents) involved eleven children aged between 7 and 9 . In regard to food, while the ideas about healthy and environmentally friendly items often overlapped (as in the case of "organic," "biological," or "home-grown" foods), other items seemed to be either good for health but not "environmentally friendly" (such as peeling fruits for the fear of chemicals in the peel, thus reducing perceived risk of "poisoning" but simultaneously wasting part of the fruit) or good for the environment but not necessarily healthy (veganism).

As far as "drink" is concerned, similar overlaps occurred as with food (for example, drinks without chemical additives such as taste enhancers were both viewed as "healthy" and "good for the environment"). Drinking tap water constituted a significant theme that divided the groups along the lines of beliefs in health safety and risks associated with factors such as "treatment chemicals." Drinking bottled water was seen as less "risky" than tap water by less than half of the parents, who evoked added "minerals," "vitamins," and particularly the "purity" as greatest health advantages. Another item discussed was "packaged juice." The children tended to think that juice was healthy although one child referred to sweeteners and "something added." When asked to elaborate on what the children perceived as healthy, a few younger children (7- to 8-year-olds) issued that the healthiness is due to "the vitamins" and "stuff that makes your bones and hair stronger" and, as a 7-year-old boy put it, "natural and good for nature."

Packaging was sometimes seen as "healthy" (protecting food from germs and other contaminants and keeping it fresh) or "unhealthy" (when packaging was thought to contain dangerous substances). In most cases, packaging was seen as "bad for the environment." An 8-year-old boy issued that packaging "lets us see where the juice comes from," and while he could not elaborate on this point, his father supplied "so we can choose not to buy juice that is flown from far away." This statement unlocked the discussion about the information on the packaging that could be either "good for health" (nutritional values) or environment (whether the product needs to be transported from afar). A 7-year-old girl supplied that if the juice needs to be "flown from afar," it is good that the package "protects it from spilling." A 9-year-old boy asked, "But cannot the packages be recycled?" which initiated the discussion on what is packaging made of, how it can be recycled or reused.

In the focus group with older children, where discussion of utilities was included, most children referred just to drinking water and were not very aware of the water used for "flushing toilet," "taking a shower," "washing hands," and "cooking"- - some naming water that was used for growing food or producing drinks they consumed. Children were aware of the electricity use, especially "the lights" and "the use of electrical items," such as TV and computers and even "electrical cars." Consumption was discussed in terms of "good or bad for others" and issues like "fair payment to poor farmers in developing countries for their produce" and "using other country's land to produce food we eat" were mentioned.

The brainstorm session yielded 23 statements and produced five clusters, as summarized in Table 2. Each statement is followed by a rating.

\section{Results: the children from school 3}

In the third school, 12 children participated in the focusgroup sessions and nine in the interviews. Themes discussed included questions of what responsible consumption is but showed that most participants did not link responsibility to consumption and did not see negative effects that consumption can have. Consumption was discussed more as a social and status marker, as "things" and "objects" that distinguish one group (like "the rich") from the other. A few children reported that their parents cannot "buy much stuff" because of financial constraints.

In the initial focus-group discussion with six children between the ages of seven and nine, the theme of food was also raised. Most categories mentioned in association with food had to do with quantity ("we have a lot of food at home") and "testiness." Testiness was often associated with home cooking or with ethnic group-specific cooking. A 8-year-old Moroccan supplied: "My mother make really tasty food. Sometimes my uncle brings [the ingredients] from Morocco. You cannot buy them here, it's like... special spice." A Turkish girl of eight agreed that "own spices" are the best and that she enjoys helping her mother with cooking and that food is something that "people can share with others." The idea that food is important as a way of "getting to know another culture" was enthusiastically supported. Some children asserted that "their" food was "healthier than Dutch food." When asked to clarify what they meant by "Dutch food," the children mentioned Febo (snack foods like minced meat croquettes or cheese soufflés). A few children directly argued that they like "Dutch food," especially French fries. A Turkish boy of eight supplied that fries are "not healthy because of fat." A few 
Table 2 Clustered statements and their ratings: children from schools 1 and 2

\begin{tabular}{|c|c|}
\hline Cluster 1. "Food should not damage nature" & $\begin{array}{l}\text { Food should be made without killing animals (5) } \\
\text { Food should be made without using too many plants (5) } \\
\text { Overfishing is bad for nature (5) } \\
\text { I want to be a vegetarian (4) } \\
\text { Meat is important for my health but bad for nature (3) } \\
\text { I may become a vegetarian some time (2) } \\
\text { I am a vegetarian (1) }\end{array}$ \\
\hline Cluster 2. "Packaging is not good for nature" & $\begin{array}{l}\text { Packaging is dirty (as it pollutes nature) (4) } \\
\text { Packaging uses too much space (4) } \\
\text { It's too bad packaging goes in the garbage (3) }\end{array}$ \\
\hline Cluster 3 "Things I do and how they affect the world" & $\begin{array}{l}\text { I should not eat or drink too much (3) } \\
\text { Eating too much is bad for nature (3) } \\
\text { Eating other animals is not good (2) } \\
\text { Eating "vegetables" [plants] is not good (1) } \\
\text { If I eat all plants, there will be nothing left for animals to eat (1) }\end{array}$ \\
\hline $\begin{array}{l}\text { Cluster 4. "Things that are (not) } \\
\text { good for others or yourself" }\end{array}$ & $\begin{array}{l}\text { If we eat too much here, the children in Africa will have no food [left] (1) } \\
\text { If you eat or drink too much, there isn't too much food left in the world (1) } \\
\text { Nature cannot always produce more for others (1) } \\
\text { If you are fat, it's unhealthy (1) } \\
\text { Eating meat is unhealthy (1) } \\
\text { If you eat too much, you become fat (1) } \\
\text { Eating enough is important for everybody (1) }\end{array}$ \\
\hline Cluster 5. "Trade-offs" & $\begin{array}{l}\text { My parents never use their car, so we can sometimes take an airplane-and } \\
\text { that saves energy (1) } \\
\text { We pack our car full [of groceries], this way dad says we know what } \\
\text { we need per week... and don't buy too much (1) } \\
\text { If you use less electricity, you can do other things (1) }\end{array}$ \\
\hline
\end{tabular}

children mentioned the fact that they do not eat snack food because of their "culture" (meaning, for examples, that they only eat Halal). Halal meat was said to be "healthy" and "good." In this predominantly Muslim group, neither of the children ate pork, as "pigs are dirty animals." Drinking did not constitute a significant theme, nor was water consumption discussed in any detail, although "drinking alcohol" was seen as a "very bad thing" by a number of children.

Discussion of utilities supplied a number of widely supported statements associated with energy saving. An 8-year-old boy reflected: "My parents try to save electricity... because it costs too much money." Another 8-year-old boy supplied: "My father says I should not stand in the shower too long as he has to pay water bills."

As in the case of the focus-group themes, discussed with the children from first and second schools, packaging and waste was an important item. Although packaging was initially discussed from the esthetic point or "added value" of view ("beautiful," "bright," and a serial box with the "labyrinth game on the back cover"), the discussion soon veered toward packaging seen primarily as "garbage," "litter," and "waste." A 9-year-old Antillean boy offered: "It's waste... it's wasteful to through away [the packaging]."

The brainstorm session yielded 20 statements and produced seven clusters as indicated in Table 3.

\section{Comparison}

Comparison of the clusters shows that children from different schools attach different meanings to consumption. In the case of children from schools 1 and 2, consumption is linked to the actual consumed items, such as food and packaging. Consumption is seen as having bad effects on nature, and in some cases on health, as witnessed by first and largest cluster, "Food should not damage nature." In the case of school 3, at least judging on the basis of the first two clusters, consumption is seen as a good thing, considering the dominance of the first cluster, "Consumption is about having a good life." Consumption is also linked to 
Table 3 Clustered statements and their ratings: children from school 3 Cluster 1. "Consumption is about
having a good life"

Cluster 2. "Things I want to have"

Cluster 3 "Saving money"

Cluster 4. "Good food"

Cluster 5. "Making others jealous"

Cluster 6. "Consumption and health"

Cluster 7. "Packaging is bad"
Consumption means you can buy good things (5)

Consuming means you can have a good life (4)

Consumption is about having stuff you want (4)

Rich people can buy more and are happy (2)

Rich people can buy nice cars (2)

I would like to have a good car when I am older (5)

I would buy a lot of nice clothes when I have money (5)

I want a new play station (4)

I want to have all the toys they sell in a toy shop (1)

We should not buy too much [stuff] to save money (3)

My parents buy cheap clothes to save money (1)

We cannot buy much to save money (1)

My parents turn off lights to save electricity (1)

I want to save [pocket] money to buy a laptop (1)

My mother's cooking is the best (4)

My own culture [ethnic] food is best (4)

Best food comes from my own country [region] (2)

I can eat a lot of good food (1)

If you can have many things, it makes others jealous (1)

I don't want to have things that make others jealous (1)

I don't like it when somebody shows off what they have (1)

Being fat is unhealthy (1)

Eating too much is unhealthy (1)

Eating [pork] meat is unhealthy (1)

Packaging causes litter (1)

Packaging is not recycled (1)

They shouldn't make all these wrappers (1) social status and freedom, negative effect of having (too much) waste is not acknowledged, except for in cluster 7, "Packaging is bad." While children from schools 1 and 2 felt that they had a certain influence over the "world" ("Things I do and how they effect the world"), there is no realization of own power and agency acknowledged by children from school 3.

Largest overlaps are found in clusters associated with consumption and health (particularly eating too much being seen as unhealthy) and clusters associated with packaging being wasteful. Cluster 4 for the first and second schools, "Things that are (not) good for others or yourself" and cluster 6 for the third school, "Consumption and health" contained overlapping items associated with unhealthy effects of overeating. However, while not eating meat is associated with ethical considerations for a child from the first school, not eating pork is associated with religious considerations for a child from the third school. "Packaging is not good for nature"-second cluster for schools 1 and 2 and cluster 7 for the third school contained similar statements.

Social and environmental responsibility was clearly present in statements from children from first and second schools and completely absent from the third school children. Aside from perceiving consumption as problematic, they also linked their own consumption to society at large. Children from the third school also saw consumption as a social concept, but more in relation to "close circle" ("Making others jealous"), but also as a marker of societal standing in association with "good life." The cluster "saving money" is only present in the children from the third school, as well as "wanting to have things."

It appears that the hypothesis that the children from disadvantaged socioeconomic background do indeed report that their parents exhibit more pro-environmental behaviors (such as reportedly buying less and saving electricity), but only as related to economically motivated choices. They also demonstrate low interest in the principle of responsible consumption and lower environmental concern. In fact, for the children in the sample from the third school, (increased) consumption was seen as something to be desired, rather than avoided. Children from the first two schools exhibit both concern and guilt in relation to consumption, but also high awareness of the influence of their individual (consumption) choices on society. 
Further research needs to expand and validate these findings. The scale of this article does not allow for more detailed comparison, but we may reflect that the differences in clusters are not necessarily indicative of the actual fundamental understanding of consumption by children from different socioeconomic backgrounds. It would be wrong to assume that children from the first two schools did not "want to have things" any less than children from the third school. The differences can be attributed to a number of factors, such as the influence of the parents and peers, presence of stronger environmental education (EE) curriculum in the first two schools, and the group dynamics within the focus groups. Investigation into the cause of these differences is very important; thus, further and deeper research seems warranted.

In the evaluative meeting with the children, parents, and teachers discussing the concept mapping results, the research participants expressed their interest in the development of the pilot program on consumption in their schools. Findings from this research need yet to be incorporated into the larger framework of educational program about "responsible consumption." Implications for the curriculum targeted at responsible consumption can be manyfold, but they will also depend on ethical considerations. For example, it can be argued that the children from the third school need more basic information about the relationship between the consumption and environmental and social consequences. On the other hand, elevating a sense of guilt associated with consumption in some of the children from the first and second schools might be yet another objective.

\section{Next step: developing curriculum}

The Sustainable Teacher's Colleges Foundation (DHO) in the Netherlands has developed an online forum that addressed responsible consumption but has not (yet) discussed it in relation to school curriculum due to the lack of "background knowledge." The results of this study are a starting point for the development not only of such a knowledge foundation, but they also provide provisional topics that may be incorporated in the upper elementary school curriculum. Consumption could be addressed through incorporating it into the subjects related to economic awareness and history (in as far as the consequences of, for example, industrial revolution and mass production of goods are concerned), and subjects in exact sciences ranging from biology (for example, placing human consumption in the context of food chain, metabolism, and waste) to chemistry (for example, what constitutes "food").

Clusters outlined in the results of this study could serve as a basis of incorporating yet another topic, the cradle-to-cradle principle, either as part of the existing modules, as outlined above, or as a separate course for which teachers' training will be required. The cradleto-cradle principle refers to the concept developed by the American architect William McDonough and the German chemist Michael Braungart in their influential book "Cradle to Cradle: Remaking the way we make things" (2002). The authors succeeded in producing a number of designs, ranging from construction to textiles (often based on preindustrial knowledge of "natural" building materials or "organic" clothing) that not only brought them commercial success and recognition, but also established cradle-tocradle $(\mathrm{C} 2 \mathrm{C})$ practices and organizations across the globe. The "waste equals food" idea developed by the authors can be of practical importance for the upper elementary school course aimed at critical and yet positive learning about consumption. Ethical considerations, implicit in the research presented in this article, such as the need to avoid guilt feelings about consumption in favor of positive learning, may be addressed through the application of the cradle-to-cradle principle.

Yet another principle of responsible consumption curriculum can be fostering not only "private sphere" activism (concentrated on private consumption choices such as limiting the amount of consumed items), but accent on "public sphere" environmentalism (for discussion of the private and public spheres of environmentalism, see Stern 2000). Curriculum for responsible consumption may also include learning about public actions, when young people learn how to pressure "Government and industry to act for a common good" (Chawla and Cushing 2007:438). According to Hines et al.'s (1987) analysis of determinants of pro-environmental behavior, significant variables were the knowledge of issues; knowledge of action strategies; locus of control; attitudes; verbal commitment; and sense of responsibility. The program on consumption will need to target all these areas. Children especially from the third school, who exhibited little awareness of their own influence on the world (through consumption), could perhaps best profit from empowerment and the idea that their private as well as collective action can lead to positive societal change.

The children in the age category for this research are just entering the stage of learning basic historical and political subjects that may be crucial for their active citizenship involvement in the quest for sustainable future. Understanding different experiences, attitudes, and behaviors of young people in regard to consumption will inform strategic choices involved in designing the best-suited program on consumption. Understanding different barriers that children from diverse socioeconomic backgrounds face can also lead to more differentiated educational program targeted at understanding and removing group-specific barriers. 


\section{Conclusion}

The ethnographic data on children's consumptive practices and perceptions are largely lacking, and wider research into sociocultural determinants of consumptive behavior and environmental awareness is needed to provide a foundation for incorporating consumption into environmental education (EE) program. This research did not try to exhaust but rather to open up some of the possibilities for studying attitudes of children from different socioeconomic backgrounds toward consumption. This research supports the hypothesis that the children from lower socioeconomic status group report more pro-environmental behaviors and lower consumption patterns associated with financial constraints, but also less environmental awareness than the members of more economically well-to-do groups.

The ethnographic data on children's consumptive attitudes are lacking, and more vigorous research is needed to provide a foundation for incorporating responsible consumption into EE. This study have only opened the first page in the vast and growing repository of research on environmental and consumption attitudes in children and how important socioeconomic background can be in determining these attitudes. The study of the social influences of children's peers, parents, teachers, and socioeconomic background in their consumption choices requires further investigation, involving a diversified methodological toolkit.

The concept mapping methodology can be used as a foundation for the development of the educational program by providing a framework for responsible consumption, for example by explaining the cradle-to-cradle principle. Similarly to the case of teaching complex issues such as climate change, teaching consumption provides an ideal context for introducing pupils to complex systems of the real world and connecting them to economic, socialpolitical, and technical systems. While some of the Dutch EE programs supported by the Dutch ministries of Agriculture, Environment, Water, and Education developed some of the themes related to educating for a sustainable world, consumption is not (yet) discussed in relation to school curriculum. On the basis of the results of this study, a consumption curriculum design is needed to include the topics outlined in the clusters generated by concept mapping system: general awareness of consumption (both global and local), social responsibility in regard to consumption, environmental awareness of consumed items, awareness of energy and water use (as well as other types of consumption that were not part of this study, such as transport), and environmental responsibility in regard to waste.

In order to assess the success of educational program addressing consumption, the same methodology for the baseline measurement of consumptive patterns and attitudes can also be used to measure the success of educational program on consumption.

Open Access This article is distributed under the terms of the Creative Commons Attribution Noncommercial License which permits any noncommercial use, distribution, and reproduction in any medium, provided the original author(s) and source are credited.

\section{References}

Anderson BA, Romani JH, Phillips H, Wentzel M, Tlabela K (2007) Exploring environmental perceptions, behaviors and awareness: water and water pollution in South Africa. Popul Environ 28(3):133-161

Aronson E, O’Leary M (1982) The relative effectiveness of models and prompts on energy conservation: a field experiment in a shower room. J Exp Syst 12:219-224

Baiocchi G, Minx J, Hubacek K (2010) The impact of social factors and consumer behavior on carbon dioxide emissions in the United Kingdom. J Ind Ecol 14(1):50-72

Bourdieu P (1984) Distinction: a social critique of the judgement of taste. Routledge and Kegan Paul, London

Burn SM (1991) Social psychology and the stimulation of recycling behaviors: the block leader approach. J Appl Soc Psychol 21(8):611-629

Carrier JG, Heyman C (1997) Consumption and political economy. J R Anthropol Inst 3(2):355-373

Chawla L, Cushing D (2007) Education for strategic environmental behaviour. Environ Educat Res 13(4):437-452

Cialdini RB, Reno RR, Kallgren CA (1990) A focus theory of normative conduct: recycling the concept of norms to reduce littering in public places. J Pers Soc Psychol 58:1015-1026

Dahlberg S (2001) Using climate change as a teaching tool. Can J Environ Educat 6(1):9-17

Davies P, Lundholm C (2008) Students' conceptions of price: some issues in the development of understanding of socio-economic phenomena, paper presented at the conceptual change special interest group of the European association for research in learning and instruction Turku

Davies P, Howie H, Mangan J, Telhaj S (2002) Economic aspects of citizenship education: an investigation of students' understanding. Curric J 13:201-224

Douglas M, Isherwood B (1978) The world of goods. Penguin, Harmondsworth

Dunlap RE, Van Liere KD (1978) The new environmental paradigm: a proposed measuring instrument and preliminary results. J Environ Educat 9(4):10-19

Gardner G, Stern PC (2002) Environmental problems and human behavior, 2nd edn. Allyn and Bacon, Boston

Gonzales MH, Aronson E, Costanzo MA (1988) Using social cognition and persuasion to promote energy conservation: a quasi-experiment. J Appl Soc Psychol 18:1049-1066

Guagnano GA, Markee N (1995) Regional differences in the sociodemographic determinants of environmental concern. Popul Environ 17(2):135-149

Heckler SE (1994) The role of memory in understanding and encouraging recycling behavior. Psychol Market 11:375-392

Hines JM, Hungerford H, Tomera A (1987) Analysis and synthesis of research on responsible environmental behavior: a meta analysis. J Environ Educat 18:1-8

Hirsch J, Van Deusen Phillips S, Labenski E, Dunford C, Peters T (2011) Linking climate action to local knowledge and practice: a 
case study of diverse Chicago neighborhoods. In: Kopnina $\mathrm{H}$, Shoreman-Ouimet E (eds) Environmental anthrology today. Rotledge, New York

Hunter LM (2000) A comparison of the environmental attitudes, concern, and behaviors of native-born and foreign-born US residents. Popul Environ 21(6):565-580

Isenhour C (2010) On conflicted Swedish consumers, the effort to stop shopping and neoliberal environmental governance. J Consum Behav 9:454-469

Kahn PH Jr, Fridman B (1995) Environmental views and values of children in an inner-city black community. Child Dev 66(5):1403-1417

Kahn PH, Kellert SR (2002) Children and nature. MIT Press, Cambridge

Kane M, Trochim WMK (2007) Concept mapping for planning and evaluation. Sage Publications Inc, Thousand Oaks

Kopnina H (2011) What about that wrapper? Using consumption diaries in green education. In: Kopnina $\mathrm{H}$, Shoreman-Ouimet $\mathrm{E}$ (eds) Environmental anthropology today. Routledge, New York

Kopnina H, Keune H (2010) Health and environment: social science perspectives. Nova Science Press, New York

Korhonen K, Lappalainen A (2004) Examining awareness of children and adolescent in the ramomafana region, Madagascar. Environ Educat Res 10(2):195-216

Lampert M, Van Duin S, Shuurman J (2010) Young Mentality en Duurzaamheid: Practische handvatten voor het communeceren met jongeren in de NME-sector. [Young mentality and sustainability: practical tips for communicating with adolescents in the environmental education sector]. YoungWorks publication, The Netherlands

Leiser D, Halachmi RB (2006) Children's understanding of market forces. J Econ Psychol 27(1):6-19

Lilienfeld RM (1998) Use less stuff: environmentalism for who we really are. Ballantine Publishing Group, New York

Louv R (2005) Last child in the woods: saving our children from nature-deficit disorder. Algonquin books of Chapel Hill, North Carolina

Manoli CC, Johnson B, Dunlap RE (2007) Assessing children's environmental worldviews: modifying and validating the new ecological paradigm scale for use with children. J Environ Educat 38(4):3-13
Mayer SF, McPherson FC (2004) The connectedness to nature scale: a measure of individuals' feeling in community with nature. J Environ Psychol 24:503-515

McDonough W, Braungart M (2002) Cradle to cradle: remaking the way we make things. North Point Press, New York

Miller D (1995) Consumption studies as the transformation of anthropology. In: Miller D (ed) Acknowledging consumption: a review of new studies. Routledge, London

Ölander F, ThØgersen J (1995) Understanding of consumer behaviour as a prerequisite for environmental protection. J Consum Policy 18(4):345-385

Pallak MS, Cook DA, Sullivan JJ (1980) Commitment and energy conservation. In: Bickman's L (ed) Applied social psychology annual. Sage, Beverly Hills

Pffefer MJ, Stycos JM (2002) Immigrant environmental behaviors in New York City. Soc Sci Q 83(1):64-81

Ritenbaugh K (1984) Household refuse analysis: theory, method, and applications in social science. Sage Publications, Beverly Hills

Sahlins M (1976) Culture and practical reason. University of Chicago Press, Chicago

Sevón G, Weckström S (1989) The development of reasoning about economic events: a study of finnish children. J Econ Psychol 10:495-514

Shepardson DP, Niyogi D, Choi S, Charusombat U (2009) Seventh grade students' conceptions of global warming and climate change. Environ Educat Res 15(5):549-570

Shove E, Trentmann F, Wilk R (2009) Time, consumption and everyday life: practice, materiality and culture. Berg, Oxford

Stern PC (2000) Toward a coherent theory of environmentally significant behavior. J Soc Issues 36:407-424

Vining J, Linn N, Burdge RJ (1992) Why recycle? A comparison among recycling motivations in four communities. Environ Manage 16:785-797

Wells NM, Lekies KS (2006) Nature and the life course: pathways from childhood nature experiences to adult environmentalism. Child Youth Environ 16(1):1-24

Wilk RW (1982) Household archeology. Am Behav Sci 25(6): 617-639 